\title{
The ultrasound-guided intratissue percutaneous electrolysis (epi®) for the treatment of refractory- neovascular patellar tendinopathy
}

\section{Introduction}

Refractory patellar tendinopathy (RPT) is a chronic disease with progressive degeneration of extracellular matrix, microtearing, and loss of tendon micro architecture as a hallmark. The essential pathologic lesion of tendinopathy is often described as a failed healing response of the tendon, and persistence of the lesion is attributed to the tissue anchored in the proliferative or angiogenic phase, as shown in histopathology. ${ }^{1}$

Structural findings of collagen degeneration and angiofibroblastic neoplasia have been well described and are now referred to as "neovascular tendinosis." The presence of neovascularization has been theorized to cause pain in patients with tendinopathy. ${ }^{2}$ Recent studies have examined the role of neo-vessels and neo-innervations on chronic tendon pain and dysfunction, and interventions targeting this process have reported favorable outcomes in RPT.

Ultrasound-guided Intratissue percutaneous electrolysis (EPI®) treatment is the application of a direct current (DC) whose catodic flow is transferred to the area of the degenerative tendon using an acupuncture needle. ${ }^{4}$ This accumulated electrical charge (AEC) in the degenerative tissue will produce the activation of the molecular, cellular and biological processes necessary to restore the regeneration mechanisms of the tendon. In recent studies it has been demonstrated that $E P I{ }^{\circledR}$ technique is effective in tendinopathy and sport muscular injuries. $^{5-7}$

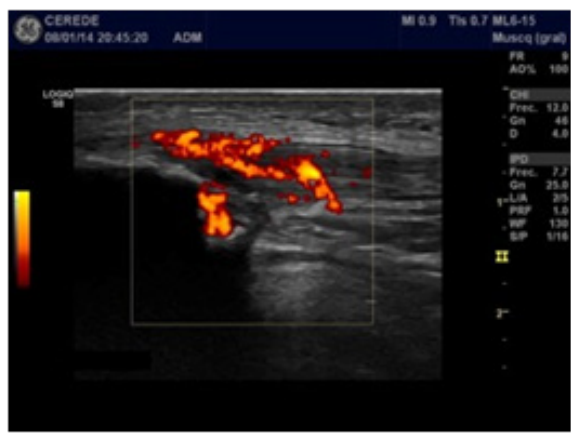

Figure I Ultrasound image with power doppler. Longitudinal view of a Patellar neovascular tendinopathy, with thickening of the tendon and hipoecoic image.

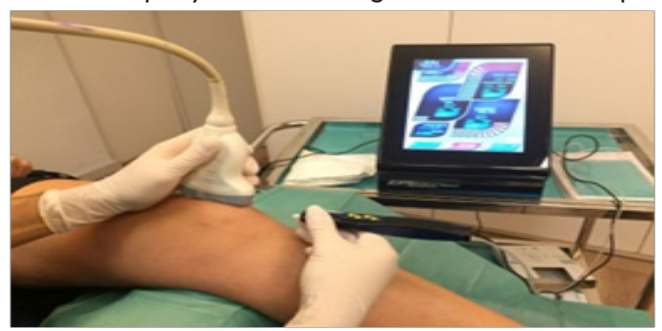

Figure 2 Patellar tendinopathy treatment using EPI $($ device (EPI advanced S.L. Barcelona, Spain).
Volume 4 Issue I- 2017

Jose Manuel Sánchez-lbáñez

Department of Invasive Physiotherapy in Sports Injuries. Universitat de Lleida, Spain

Correspondence: Dr. Jose Manuel Sánchez-lbáñez, CEREDE Barcelona Clinic, Spain, Email drsanchez@cerede.es

Received: December 02, 2016 | Published: January 05, 2017

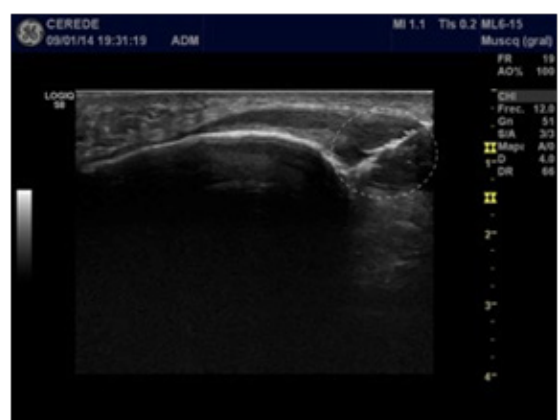

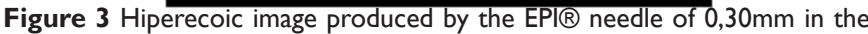
degenerative area of the tendon. This hiperecoic image corresponded to a gas density produced by the electrochemical response of the catodic flow (CF) in the degenerative extracellular matrix.

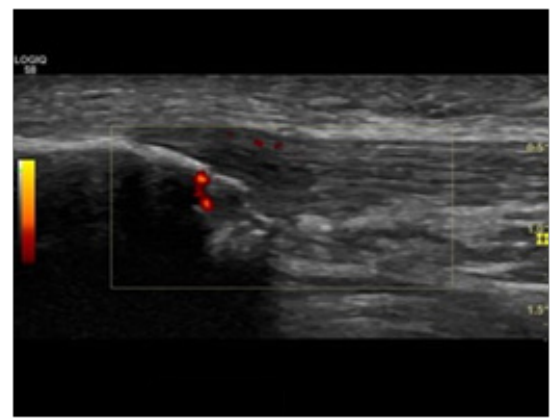

Figure 4 Ultrasound image in longitudinal view and colour doppler two week after the $\mathrm{EPI} \circledast{ }^{\circ}$ technique treatment ultrasound-guided. It is observed the degenerated area of the tendon that is substituted by a new connective tissue and decrease the neovascular effect.

\section{Acknowledgements}

None.

\section{Conflict of interest}

The author declares no conflict of interest. 


\section{References}

1. Andia I, Maffulli N. Clinical outcomes of biologic treatment for chronic tendinopathy. Operative Techniques in Orthopaedics. 2016;26(2):98-109.

2. Hoksrud A, Torgalsen T, Harstad H, et al. Ultrasound-guided sclerosis of neovessels in patellar tendinopathy: a prospective study of 101 patients. Am J Sports Med. 2012;40(3):542-547.

3. Ohberg L, Alfredson H. Ultrasound guided sclerosis of neovessels in painful chronic Achilles tendinosis: pilot study of a new treatment. $\mathrm{Br} J$ Sports Med. 2002;36(3):173-177.

4. Sànchez-Ibàñez JM, Fernàndez ME, Moreno C, et al. Ultrasound-Guided EPI ${ }^{\circledR}$ technique and eccentric exercise, new treatment for Achilles and Patellar tendinopathy focused on the region-specific of the tendon. Orthop Muscular Syst. 2015;4:200.
5. Sánchez-Ibáñez JM, Alves R, Polidori F, et al. Effectiveness of ultrasoundguided EPI ${ }^{\circledR}$ technique in the treatment of insertional patellar tendinopathy in soccer players. Br J Sports Med. 2003;47(9):e2.

6. Sánchez-Ibáñez JM. Ultrasound guided percutaneous electrolysis (EPI®) in patients with chronic insertional patellar tendinophaty: a pilot study. Knee Surg Sports Traumatol Arthrosc. 2008;16:220-221.

7. Sanchez-Ibañez JM, Colmena C, Benabent J, et al. New technique in tendon sport recovery. Percutaneous electrolysis intratissue (EPIß). Int $J$ Phys Med Rehabil. 2013;1:113. 